\title{
Conseqüências no crescimento de maxila e mandíbula de defeito ósseo cirúrgico no ramo da mandíbula de ratos ${ }^{1}$
}

\author{
Consequences on the growth of maxilla and mandible of surgical bone defect on \\ mandibular ramus of rats
}

\section{Lucimar Rodrigues ${ }^{2}$, Luciane Toshie Miyazaki ${ }^{3}$ João Gualberto de Cerqueira Luz ${ }^{4}$}

1. Trabalho realizado no Laboratório Experimental do Departamento de Cirurgia, Prótese e Traumatologia Maxilo-Faciais da Faculdade de Odontologia da Universidade de São Paulo (FOUSP).

2. Mestre em Cirurgia e Traumatologia Buço Maxilo Facial - FOUSP.

3. Estagiária da Disciplina de Traumatologia Maxilo Faciais - Departamento de Cirurgia, Prótese e Traumatologia Buco Maxilo Faciais - FOUSP.

4. Professor Associado do Departamento de Cirurgia, Prótese e Traumatologia Buco Maxilo Faciais - FOUSP.

\section{RESUMO}

OBJETIVO: Analisar as conseqüências no crescimento de maxila e mandíbula de defeito ósseo cirúrgico simulando fratura no ramo da mandíbula.

MÉTODOS: Foram utilizados 25 ratos Wistar com um mês de idade. Sob anestesia geral e por meio de incisão submandibular. Foi realizada osteotomia vertical no ramo da mandíbula do lado direito com emprego de motor cirúrgico. Após período de dois meses os animais foram sacrificados, os tecidos moles retirados e as hemimandíbulas desarticuladas. Foram realizadas incidências radiográficas axiais para o crânio e laterais para as hemimandíbulas. A seguir, por intermédio de um sistema de computador foram obtidas medidas lineares da maxila e das hemimandíbulas. Foi empregado o teste “t” de Student para verificação da significância da diferença entre os lados experimental e controle.

RESULTADOS: A diferença foi significante para a altura do ramo $(p=0,010)$ e comprimento da mandíbula referente ao côndilo $(p=0,015)$ e ao ângulo $(p<0,001)$, não havendo diferença significante para as mensurações da maxila.

CONCLUSÃO: As conseqüências do defeito ósseo cirúrgico experimental no ramo da mandíbula na fase de crescimento foram a diminuição da altura do ramo e do comprimento da mandíbula.

DESCRITORES: Mandíbula. Fraturas mandibulares. Desenvolvimento maxilofacial.

\section{ABSTRACT}

PURPOSE: To analyse the consequences on the growth of maxilla and mandible of a surgical bone defect that simulates a mandibular ramus fracture.

METHODS: A group of 25 one-month-old Wistar rats were used in this study. Under general anesthesia, and through a submandibular incision, a vertical osteotomy on the right side of the mandibular ramus was made using a surgical drill. The animals were sacrificed after two months, soft tissues removed, and the mandible disarticulated. The skull was submitted to axial radiograph and the hemimandibles to a lateral radiograph. With these, cephalometric mensurations were made through a computer system, and the obtained values submitted to Student's t-test. 
RESULTS: The height of the mandibular ramus presented significant difference $(p=0,010)$ as well as the length of mandible, both to the condyle $(\mathrm{P}=0,015)$ and the angle $(\mathrm{p}=0,001)$. There was no significant difference to the mensurations of the maxilla.

CONCLUSION: The consequences of the experimental surgical bone defect on the mandibular ramus in the growing period were the lessening of the mandibular height and length.

KEY WORDS: Mandible. Fracture mandibular. Maxillofacial development.

\section{Introdução}

As fraturas mandibulares estão entre os principais sítios de ocorrência de fraturas maxilofaciais. Casuísticas têm demonstrado representarem cerca de $22 \%$ a $50 \%$ dos casos, estando entre os locais de maior freqüência ${ }^{1,2}$. Deve ser destacado que $20 \%$ dos casos de fraturas mandibulares são representados por crianças com menos de 15 anos de idade $^{3,4}$. São verificadas alterações a menor em altura e comprimento da mandíbula em fratura experimental de ângulo de mandíbula ${ }^{6}$. Em um estudo experimental de fratura do corpo da mandíbula, na fase de crescimento ocorreu diminuição da altura e comprimento da mandíbula, bem como do comprimento da maxila ${ }^{7}$. Estudos baseados em fraturas condilares demonstraram alterações a menor no crescimento mandibular, e em menor grau nas fraturas de corpo e ângulo mandibular ${ }^{6,8}$.

O objetivo deste estudo foi analisar as conseqüências no crescimento de maxila e mandíbula de defeito ósseo cirúrgico simulando fratura no ramo da mandíbula.

\section{Métodos}

\section{Amostra}

Foram utilizados 25 Rattus norvegicus, linhagem Wistar, machos com idade de um mês e pesando em média 78g. Os animais receberam ração comercial granulada para roedores (Labina, Agribrands Purina) e água ad libitum. O manuseio dos animais foi de acordo com os princípios éticos propostos pelo Colégio Brasileiro de Experimentação Animal, sendo a proposta deste trabalho aprovada pelo Comitê de Ética em Pesquisa da Instituição.

\section{Procedimentos}

Os animais foram submetidos ao mesmo procedimento cirúrgico, sendo utilizadas para a intervenção xilazina (Rompum, Bayer) na dose de $10 \mathrm{mg} / \mathrm{kg}$ de peso corporal e quetamina (Ketalar, Parke-Davis) na dose de $25 \mathrm{mg} / \mathrm{kg}$ de peso corpora,l aplicados via intraperitoneal. Em seguida, foi realizada tricotomia, seguida de anti-sepsia com polivinilpirrolidona-iodo. O acesso cirúrgico ao ramo da mandíbula foi obtido por uma incisão na região submandibular do lado direito. Uma ferida óssea bicortical, no sentido vertical e na altura do ângulo mandibular, foi obtida com motor de baixa rotação e broca número 701 de carbide sob refrigeração com soro fisiológico. Concluindo o ato cirúrgico, sutura por planos foi realizada com fio de náilon monofilamento 5.0 agulhado. Após a conclusão, foi aplicado antibiótico benzilpenicilina procaína (Wycillin-R, Weyth), na dose de 40000 U.I./Kg/dia, durante 7 dias.

Nas duas primeiras semanas de pós-operatório os animais foram alimentados com ração fragmentada e, a seguir, na sua apresentação normal. Com três meses de idade, os animais foram sacrificados por dose letal de anestésico geral. A seguir, todas as cabeças foram removidas, sua pele e tecidos moles retirados, a mandíbula desarticulada e as hemimandíbulas separadas por meio da sínfise fibrosa, sendo que crânio e hemimandíbulas foram fixados em formol a $10 \%$.

Mensurações cefalométricas por radiografias

Para a realização do exame radiográfico foi utilizado aparelho de raios X odontológico (Spectro II, Dabi-Atlante), no regime de $56 \mathrm{kV}, 10 \mathrm{~mA}$, sendo o tempo de exposição de 0,5 segundos para o crânio e de 0,4 segundos para as hemimandíbulas e filme radiográfico do tipo periapical, com incidências axial para o crânio e norma lateral para as hemimandíbulas.

Foi utilizado um sistema computadorizado para a obtenção das mensurações que foram feitas no Laboratório de Informática Dedicado à Odontologia 
(LIDO). Aaquisição e o processamento das imagens radiográficas foram obtidas através da retina eletrônica do Fotovix II (Tamron Co., Japão) e transferidas para o microcomputador através da placa Iris 16 (Microimagem) e digitalizadas pelo programa (software) ImagemLab, calibrado em milímetros que permitiu a realização de mensurações lineares e angulares de pontos reproduzíveis.

Na incidência axial do crânio seco (Figura 1), para os lados direito e esquerdo foram mensuradas: a distância entre o forame infra-orbital e o ponto incisal (FI-PI), a distância entre a bula timpânica e o forame infra-orbital (BT - FI) e a distância entre a bula timpânica e a raiz mesial do primeiro molar (BT - RM), referentes ao comprimento da maxila. $\mathrm{Na}$ incidência de norma lateral das hemi-mandíbulas (Figura 2), para os lados direito e esquerdo foram utilizadas as seguintes mensurações: referentes à sua altura a distância entre a intersecção da face distal do terceiro molar inferior com o ramo da mandíbula e a incisura antegônica, representada pelo entalhe na base da mandíbula localizado anteriormente ao ângulo da mandíbula (TM - IA) e a distância entre o processo condilar e o processo angular (PC $-\mathrm{PA}) \mathrm{e}$ referentes ao seu comprimento a distância entre a inserção do incisivo no osso e o processo angular ( II - PA ) e a distância entre a inserção do incisivo no osso e o processo condilar (II-PC).

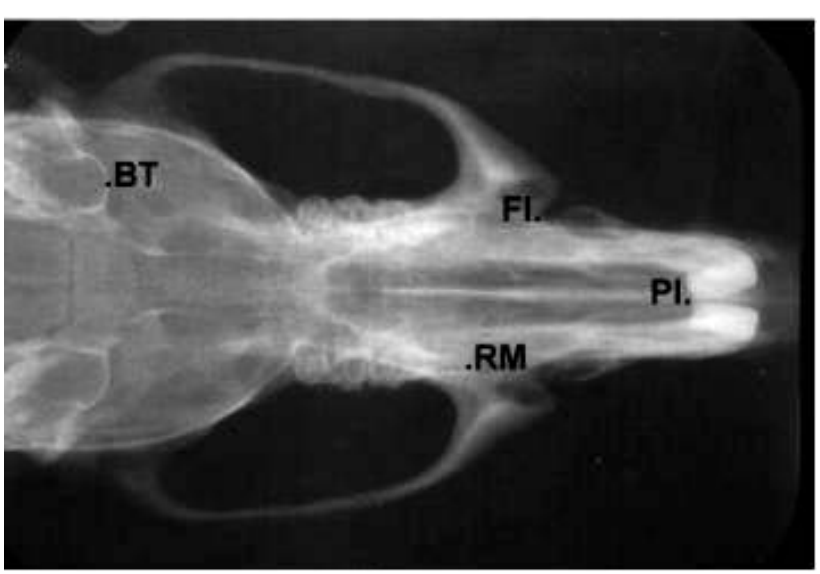

FIGURA 1 - Incidência axial do crânio seco. $\mathrm{PI}=$ ponto incisal; FI = forame infra-orbitário; $\mathrm{RM}=$ raiz mesial do primeiro molar $\mathrm{BT}$ = bula timpânica

\section{Análise estatística}

Os dados obtidos foram tabulados e receberam tratamento estatístico por meio do programa SPSS(Statistical Package for Social Science) versão 8.0 para Windows. Foi utilizado o teste "t" de Student para dados pareados, para a comparação entre variáveis dos lados direito e esquerdo. Foi fixado o nível de significância de $5 \%(\mathrm{p} \leq 0,050)$ para o teste estatístico.



FIGURA 2 - Incidência lateral das hemimandíbulas.

$\mathrm{PI}=$ ponto incisal; FI = forame infra-orbitário; $\mathrm{RM}=$ raiz mesial do primeiro molar BT = bula timpânica

\section{Resultados}

Todos os animais tiveram cicatrização satisfatória e apresentaram ganho de peso até o período do sacrifício. Na análise macroscópica foi observada discreta assimetria facial para o lado operado (Tabela 1).

1.Distância forame infra-orbitário - ponto incisal

Os valores médios da distância entre o forame infra-orbitário e o ponto incisal para os lados direito e esquerdo são observados na Tabela 1 . Com a aplicação do teste " $t$ ” de Student - pareado - não houve diferença significante na comparação entre os lados direito e esquerdo $(\mathrm{p}=0,481)$.

2. Distância bula timpânica - forame infraorbitário

Os valores médios da distância entre a bula timpânica e o forame infra-orbitário para os lados direito e esquerdo são observados na Tabela 1 . Com a aplicação do teste " $t$ ” de Student - pareado - não houve diferença significante na comparação entre os lados direito e esquerdo $(\mathrm{p}=0,363)$. 
3. Distância bula timpânica - raiz mesial do primeiro molar

Os valores médios da distância entre a bula timpânica e a raiz mesial do primeiro molar para os lados direito e esquerdo são observados na Tabela 1. Com a aplicação do teste "t" de Student -pareado - não houve diferença significante na comparação entre os lados direito e esquerdo $(p=0,549)$.

4. Distância face distal do terceiro molar incisura antegônica

Os valores médios da distância entre a face distal do terceiro molar e a incisura antegônica para os lados direito e esquerdo são observados na Tabela 2. Com a aplicação do teste “ $t$ ” de Student -pareado - não houve diferença significante na comparação entre os lados direito e esquerdo $(\mathrm{p}=0,053)$.

5. Distância processo condilar - processo angular

Os valores médios da distância entre o processo condilar e o processo angular para os lados direito e esquerdo são observados na Tabela 2. Com a aplicação do teste " $t$ ” de Student -pareado - houve diferença significante na comparação entre os lados direito e esquerdo $(p=0,010)$.

6. Distância inserção do incisivo - processo angular

Os valores médios da distância entre a inserção do incisivo e o processo angular para os lados direito e esquerdo são observados na Tabela 2. Com a aplicação do teste " $t$ ” de Student -pareado - houve diferença altamente significante na comparação entre os lados direito e esquerdo $(\mathrm{p}<0,001)$.

7. Distância inserção do incisivo - processo condilar

Os valores médios da distância entre a inserção do incisivo e o processo condilar para os os lados direito e esquerdo são observados na Tabela 2 . Com a aplicação do teste "t" de Student -pareado - houve diferença significante na comparação entre os lados direito e esquerdo $(p=0,015)$.

TABELA 1 - Valores em milímetros das mensurações obtidas na incidência axial da axila.

\begin{tabular}{lccc}
\hline & & Mensurações & \\
\cline { 2 - 4 } & FI - PI & BT - FI & BT - RM \\
\cline { 2 - 4 } & média \pm dp & média \pm dp \pm dp \\
\hline $\begin{array}{l}\text { Lado direito } \\
\begin{array}{l}\text { Experimental } \\
\text { Lado esquerdo }\end{array}\end{array}$ & $8,29 \pm 0,67$ & $21,45 \pm 0,93$ & $18,08 \pm 0,77$ \\
\hline
\end{tabular}

FI = forame infra-orbitário, $\mathrm{PI}=$ ponto incisal, $\mathrm{BT}$ = bula timpânica $\mathrm{RM}=$ raiz mesial do primeiro molar, $\mathrm{dp}=$ desvio padrão.

TABELA 2 - Valores em milímetros das mensurações obtidas na incidência lateral das hemi-mandíbulas.

\begin{tabular}{lcccc}
\hline & \multicolumn{4}{c}{ Mensurações } \\
\cline { 2 - 5 } & TM - IA & PC - PA & II - PA & II - PC \\
\cline { 2 - 5 } & média \pm dp & média \pm dp & média \pm dp & média \pm dp \\
\hline $\begin{array}{l}\text { Lado direito } \\
\begin{array}{l}\text { Experimental } \\
\text { Lado esquerdo } \\
\text { Controle }\end{array}\end{array}$ & $6,10 \pm 0,43$ & $7,28 \pm 0,59$ & $22,72 \pm 0,91$ & $23,89 \pm 0,74$ \\
\hline
\end{tabular}

$\mathrm{TM}=$ face distal do terceiro molar , IA = incisura antegônica , PC= processo condilar, PA = processo angular, II = inserção do incisivo, $\mathrm{PA}=$ processo angular, $\mathrm{dp}=$ desvio padrão. 


\section{Discussão}

Os efeitos no crescimento de maxila e de mandíbula de defeito ósseo cirúrgico simulando fratura no ramo da mandíbula de ratos foram observados neste trabalho. Foi possível afirmar que os efeitos foram a diminuição da altura do ramo e do comprimento da mandíbula e que não houve alterações no crescimento da maxila.

Foi utilizado o exame radiográfico, por meio das incidências axial do crânio seco e lateral das hemimandíbulas, aliado a um sistema de computador, para as mensurações das alterações no crescimento da maxila e mandíbula. Esta metodologia já tem sido utilizada em outras pesquisas $7,9,10$.

A abordagem cirúrgica na fase de crescimento também pode ter efeitos negativos no crescimento da maxila e da mandíbula ${ }^{5,7}$. O descolamento do periósteo e da musculatura pelo acesso cirúrgico pode resultar em alterações de tamanho e/ou de forma da maxila e /ou mandíbula ${ }^{4,5}$. Sabe-se ainda que o periósteo tem influência no crescimento da mandíbula, pois um padrão de migração do mesmo tem sido verificado $^{11}$. Porém, outros trabalhos sugerem que somente a elevação do periósteo ou acesso cirúrgico não causa alterações de crescimento, e se ocorrer são discretas e temporárias ${ }^{12,13}$.

As alterações de altura e comprimento da mandíbula também tem sido verificadas em fratura experimental de ângulo de mandíbula com osteossíntese $^{6}$. Outro estudo, porém, mostrou que independentemente de tratamento, a própria fratura em corpo de mandíbula foi capaz de interferir no crescimento da mandíbula ${ }^{7}$. Quando é realizada a remoção do côndilo em fase de crescimento também observam-se alterações na altura do ramo e comprimento da mandíbula ${ }^{5}$. Estudos baseados em fraturas mandibulares experimentais com ou sem fixação, têm demonstrado que estas podem inibir o crescimento mandibular, o que também ocorre em menor grau diante das fraturas de corpo e ângulo mandibular, sendo que estes distúrbios de crescimento são diretamente proporcionais à intensidade do trauma e do procedimento cirúrgico ${ }^{6,14}$.

A ocorrência de crescimento compensatório da mandíbula tem sido relatada, porém o mesmo é insuficiente para evitar assimetria ${ }^{15}$. Entretanto, existem relatos de resolução natural da assimetria ${ }^{16}$. O crescimento mandibular é um produto de diferentes forças e dos agentes funcionais regionais de controle de crescimento $^{17}$. E é formado por partes relativamente independentes e de diferentes fatores ${ }^{18}$.

Neste estudo não foi verificada alteração no crescimento da maxila, provavelmente devido à ação muscular e à intensa capacidade de adaptação derivada de fatores mecânicos extrínsecos resultando em compensação no seu crescimento ${ }^{18}$. Contudo, quando o procedimento cirúrgico localiza-se em corpo ou côndilo da mandíbula, na fase de crescimento, tem sido observadas alterações no comprimento da maxila ${ }^{5,7}$. Acredita-se que isto se deve provavelmente pela intercuspidação oclusal. Na sinostose experimental unilateral das suturas fronto-nasal e fronto-pré-maxilar e conseqüente alteração de crescimento da maxila tem sido verificado que, em resposta à alteração primária da maxila, a mandíbula se adaptou desenvolvendo uma assimetria secundária com diminuição da mesma no lado operado ${ }^{19}$. Também, a desoclusão dos incisivos pode ser a principal causa de assimetria da maxila, diante da fratura de corpo de mandíbula ${ }^{8}$. Existem estudos destacando o papel da intercuspidação oclusal no controle da morfogênese crânio-facial. Quando a força é aplicada somente à maxila, deslocando-a no sentido posterior, um deslocamento semelhante ocorreria na mandíbula e vice-versa, em decorrência da intercuspidação ${ }^{17}$.

\section{Conclusão}

O defeito ósseo cirúrgico simulando fratura no ramo da mandíbula de ratos teve conseqüências no crescimento da mandíbula. Houve diferença significante para a altura do ramo, para o comprimento da mandíbula referente ao côndilo e referente ao ângulo. As mensurações da maxila não apresentaram diferença significante. Concluiu-se que as conseqüências de defeito ósseo cirúrgico experimental no ramo da mandíbula na fase de crescimento foram a diminuição da altura e do comprimento da mandíbula.

\section{Agradecimento}

Ao Prof. Dr. Moacir D. Novelli, pelo auxílio nas mensurações cefalométricas por sistema de computador. 


\section{Referências}

1. Sinn NP, Hill SC, Watson SW. Mandibular fractures.In: Foster CA, Sherman JE. Surgery of facial boné fractures. New York: Churchill-Livingstone; 1987.

2. Palma VC, Luz JGC, Correia FAZ. Freqüência de fraturas faciais em pacientes atendidos num serviço hospitalar. Rev Odontol Univ São Paulo 1995; 9:121-5.

3. Lindqvist C, Sorsa S, Hyrkäs T, Santavirta S. Maxilofacial fractures sustained in bicycle accidents. Int J Oral Maxillofac Surg 1986;15:12-8.

4. Schweinfurth JM, Koltai PJ. Pediatric mandibular fractures. Facial Plastic Surg 1998;14:31-44.

5. Rodrigues L, Luz JGC. Conseqüências da remoção do côndilo mandibular no crescimento da maxila e da mandíbula: estudo experimental em ratos. Acta Cir Bras 2001;16:15-25.

6. Wangerin K, Brahms U. Beeinflußt die frakturversorgung mit osteo synthese platten das wachstum des unterkiefers? Eine tierexperimentelle studie. Dtsch Zahnärztl Z 1990;45:789-91.

7. Rocha EMVF, Goulart AC, Goldenberg S, Luz JGC. Efeitos da fratura de corpo da mandíbula no crescimento da maxila e da mandíbula: estudo experimental em ratos jovens. Acta Cir Bras 2002;17:102-9.

8. Altonem M, Ranta R, Ylipaavalniemi P. Midface deviation due to mandibular fractures. J Maxillofac Surg 1978;6:143-7.

9. Luz JGC, Araújo VC. Rotated subcondylar process fracture in the growing animal: an experimental study in rats. Int $\mathrm{J}$ Oral Maxillofac Surg 2001; 30: 545-9.
10. Yamamoto MK, Novelli MD, Luz JGC. Effects of unilateral upper incisor extraction on facial growth of Young rats. J Nihon Univ Dent Sch 1997;39:191-5.

11. Frankenhuis Van den Heuvel THM, Maltha JC, Kuijpers -Jagtman AM, Van'T Hof MA. A longitudinal radiographic study of the periosteal migration along the growing rabbit mandible. J Dent Res 1992: 71:398-402.

12. Sa'do B,Tashiro H. The influence of periosteal elevation on mandibular growth in young rats. Int J Oral Maxillofac Surg 1989;18:175-8.

13. Cabezas N T. Aspectos do crescimento facial de coelhos, com fraturas mandibulares, após osteossínteses com microplacas de titânio [Tese Doutorado]. Universidade de São Paulo - Faculdade de Odontologia; 1996.

14. Levenets AA, Grigor'ian AS. The pathogenesis of posttraumatic deformities of the mandible in the growing organism. Stomatologia 2000;79:20-6.

15. Kantomaa T. Effect of increased posterior displacement of the glenoid fossa on mandibular growth: a methodological study on the rabbit. Eur J Orthod 1984a;6:15-24.

16. Burke PH. Serial observation of asymmetry in the growing face. Br J Orthod 1992;19:273-85.

17. Enlow DH. Crescimento facial. São Paulo: Artes Médicas; 1993.

18. Koski KL. Cranial growth centers: facts or fallacies? Am J Orthodont 1968;54:566-83.

19. Xenakis D, Rönning O, Kantomaa T, Helenius H. Reactions of the mandible to experimentally induced asymmetrical growth of the maxilla in the rat. Eur J Orthod 1995;16:15-24.

\section{Correspondência:}

Lucimar Rodrigues

Departamento de Cirurgia, Prótese e Traumatologia Buco Maxilo Faciais

Faculdade de Odontologia - Universidade de São Paulo

Av. Prof. Lineu Prestes, 2227

5508-900 São Paulo - SP

Recebimento: 23/06/2004

Revisão: 28/07/2004

Aprovação: 02/09/2004

Conflito de interesse: nenhum

Fonte de financiamento: nenhuma

\section{Como citar este artigo:}

Rodrigues L, Miyazaki LT, Luz JGC. Conseqüências no crescimento de maxila e mandíbula de defeito ósseo cirúrgico no ramo da mandíbula de ratos. Acta Cir Bras [serial online] 2004 Set-Out;19(5). Disponível em URL: http://www.scielo.br/acb [também em CD-ROM]. 